\title{
Bewerben, gewinnen - und als Covermodel strahlen!
}

Machen Sie mit und werden Sie eines unserer vier Covermodel 2017! Wie das geht? Ganz einfach: Schicken Sie uns Ihr Foto und ein paar Zeilen zu Ihrer Person - und mit etwas Glück steht schon bald unser Fotograf vor Ihrer Praxistür!

$\mathrm{O}$ bwohl die Ausschreibung noch gar nicht offiziell gestartet war, hatten uns in den letzten Monaten schon einige Zuschriften mit Bewerbungen von jungen Kollegen erreicht - ein Platz auf unserem Cover scheint also begehrt zu sein! Zögern Sie deshalb nicht und bewerben Sie sich schnell: Schicken Sie uns bis zum 31.12.2016 ein aktuelles Foto, Kontaktdaten und ein paar Zeilen über sich und ihr Leben als (angehender) Zahnarzt. Dies gilt natürlich auch, wenn Sie es in den vergangenen Jahren schon einmal versucht haben und kein Glück hatten. Und wer weiß, vielleicht sind Sie dieses Mal ja einer der strahlenden Gewinner!

Wir freuen uns auf Ihre Mail!
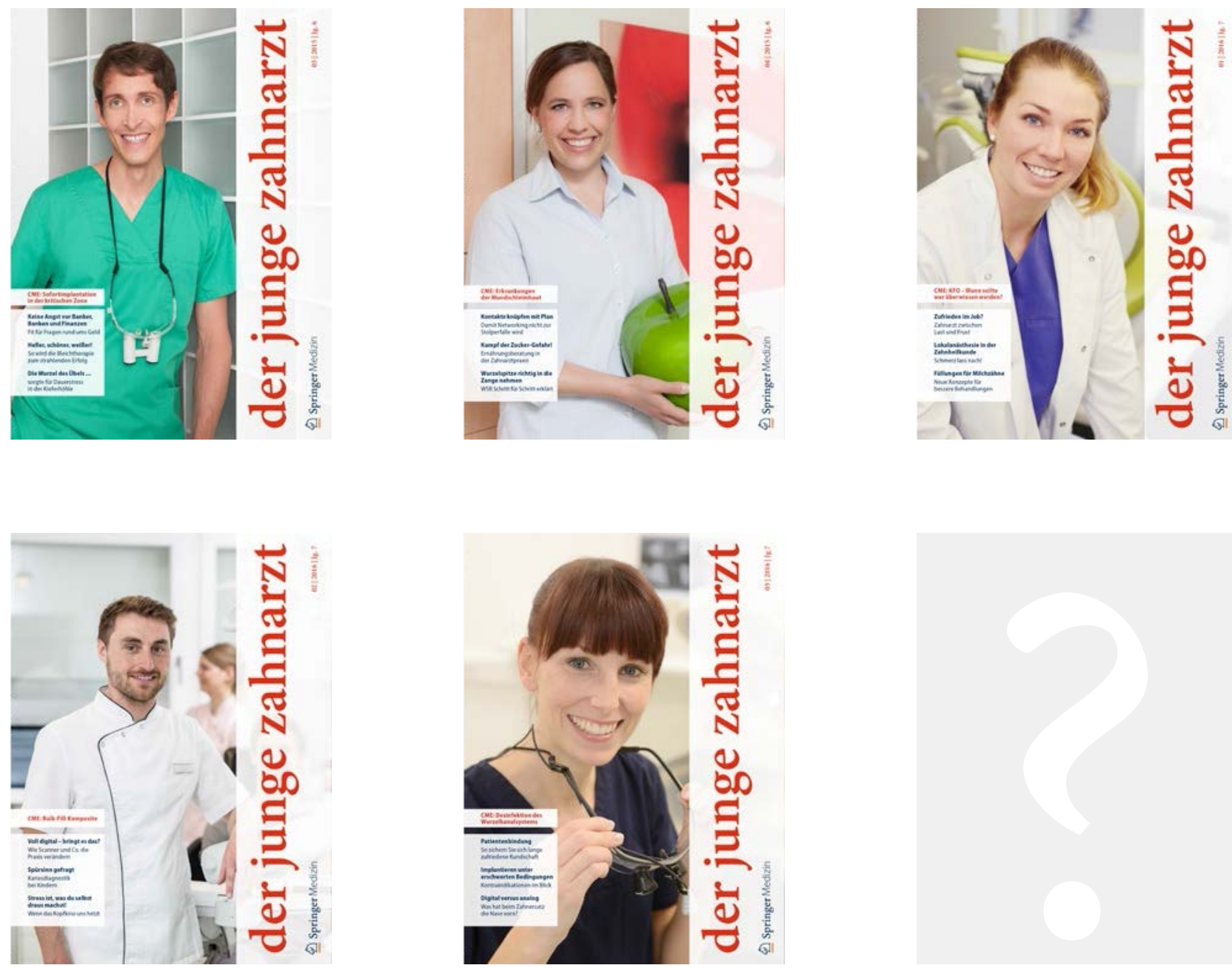

Schicken Sie Ihr Foto per Mail an: swanett.koops@springernature.com. Einsendeschluss ist der 31.12.2016. 